\title{
Obesity and Impairment in Psychosocial Functioning in Women: The Mediating Role of Eating Disorder Features
}

\author{
Jonathan M. Mond, * $\$$ Bryan Rodgers, $\dagger$ Il Phillipa J. Hay, *\| Anita Darby, * Cathy Owen, $*$ Bernhard T. Baune, * \\ and R. L. Kennedy*
}

\begin{abstract}
MOND, JONATHAN M., BRYAN RODGERS, PHILLIPA J. HAY, ANITA DARBY, CATHY OWEN, BERNHARD T. BAUNE, AND R. L. KENNEDY. Obesity and impairment in psychosocial functioning in women: the mediating role of eating disorder features. Obesity. 2007;15: 2769-2779.

Objective: The objective was to test the hypothesis that, in women, the association between obesity and impairment in psychosocial functioning is mediated by levels of weight and shape concerns and/or binge-eating frequency.

Research Methods and Procedures: Self-report measures of eating disorder psychopathology, mental health functioning, subjective quality of life in the psychological and social domains, and days "out-of-role" associated with any (physical or mental) health problem, were completed by a community sample of women classified as obese (BMI $\geq 30$ $\mathrm{kg} / \mathrm{m}^{2}, n=639$ ) or non-obese (BMI $<30 \mathrm{~kg} / \mathrm{m}^{2}, n=4253$ ). For each of the dependent measures, regression models were used to test the hypothesis of mediation by comparing the strength of the relationship between independent and dependent variables with and without inclusion of the putative mediator in the regression model.
\end{abstract}

Received for review October 23, 2006

Accepted in final form March 12, 2007.

The costs of publication of this article were defrayed, in part, by the payment of page charges. This article must, therefore, be hereby marked "advertisement" in accordance with 18 U.S.C. Section 1734 solely to indicate this fact.

*School of Medicine, James Cook University, Townsville, Australia; and †Family and Community Studies and $\$$ Medical Education Unit, Australian National University, Canberra, Australia.

§Current address: School of Psychological Science, La Trobe University, Victoria, Australia. IC Current address: National Centre for Epidemiology and Population Health, Australian National University, Canberra, Australia.

|Current address: School of Medicine, University of Western Sydney, Campbelltown, Australia.

Address correspondence to Jonathan M. Mond, School of Psychological Science, La Trobe University, Victoria, 3086 Australia.

E-mail: j.mond@latrobe.edu.au

Copyright $\odot 2007$ NAASO
Results: On each measure, the conditions for perfect mediation were satisfied when weight or shape concerns acted as the putative mediator, indicating that there was no association between obesity and functional impairment after controlling for weight or shape concerns. In contrast, associations between obesity and impairment in psychosocial functioning remained highly significant when binge-eating frequency was the putative mediator.

Discussion: The findings suggest that in women, weight and shape concerns are an important mediator of the relationship between obesity and impairment in psychosocial functioning, whereas binge eating may not be of primary importance. A greater focus on body acceptance in obesity treatment may be indicated.

Key words: binge eating, eating behaviors, quality of life

\section{Introduction}

It is well known that obesity is associated with a range of chronic medical illnesses, decreased life expectancy, and poor overall health (1). One of the most interesting findings to emerge from the obesity literature during the past decade, however, is that impairment in psychosocial functioning is generally minimal in unselected samples of obese individuals (2). Similar findings have been reported in general population samples of children and adolescents (3). These findings are somewhat surprising given the widespread stigma and discrimination associated with obesity as well as the sense of failure associated with repeated unsuccessful attempts to lose weight $(4,5)$.

At the same time, evidence from both the obesity and eating disorders fields is accumulating to suggest that quality of life is markedly impaired in certain subgroups of obese individuals, namely, the severely obese $(6,7)$, those with chronic medical conditions and/or pain $(8,9)$, those with high levels of body image dissatisfaction or weight and shape concerns $(3,10)$, and those who have recurrent epi- 
sodes of binge eating $(11,12)(1)$. The significance of binge eating, in particular, has been a focus of attention following the introduction of binge eating disorder $(\mathrm{BED})^{1}$ as a provisional diagnosis requiring further research in the DSM-IV (13). BED, a disorder characterized by recurrent episodes of binge eating without the regular use of extreme weightcontrol behaviors, affects between $2.0 \%$ and $3.0 \%$ of women (14). Like other eating disorders, it is associated with marked impairment in psychosocial functioning $(11,15)$. In addition, BED is associated with elevated levels of obesity and poor overall health $(11,15)$.

Findings from a number of studies have shown that obese individuals with BED differ from obese non-binge eaters in having higher levels of general psychological distress and functional impairment $(11,12)$. Further, these differences are accounted for by the severity of binge eating rather than the degree of obesity (11). These findings are consistent with the view that recurrent binge eating may be an important mediator of the effect of obesity on quality of life (2). However, interpretation of findings from research comparing quality of life among obese individuals with BED and obese non-binge eaters is complicated by the fact that the vast majority of this research has been conducted in clinical samples of BED patients and/or individuals seeking treatment for weight loss $(16,17)$. Because higher levels of distress and/or functional impairment associated with severe obesity and elevated levels of eating disorder psychopathology may increase the likelihood that treatment is sought, as well as the type of treatment sought, there is a need to study putative mediators of the effect of obesity on quality of life in unselected samples $(8,16,17)$.

A second problem of interpretation arises because in both community and clinical samples of obese (and non-obese) individuals, the occurrence of binge eating is typically accompanied by high levels of weight and shape concerns (18). Hence, it is possible that the elevated levels of weight and shape concerns that accompany binge eating, rather than binge eating per se, accounts for the impairment in psychosocial functioning observed in obese binge eaters. Friedman et al. (10), in a sample of severely obese individuals attending a residential weight-loss facility, found that the association between overweight and negative affect was partially mediated by participants' levels of body image dissatisfaction. Further, these effects remained significant after a measure of binge eating severity was included in the regression models. However, the generalizability of these findings was limited by the use of a treatment-seeking

\footnotetext{
${ }^{1}$ Nonstandard abbreviations: BED, binge eating disorder; ACT, Australian Capital Territory; EDE-Q, Eating Disorder Examination Questionnaire; SF-12, Medical Outcomes Study Short-Form Disability Scale; MCS SF-12, Mental Component Summary Scale; DOR, "days out-of-role"; WHOQOL-BREF, World Health Organization Quality of Life Brief Assessment Scale; QOL-P, WHOQOL-BREF Psychological Health subscale; QOL-S, WHOQOLBREF Social Relationships subscale; DV, dependent variable; IV, independent variable; M, putative mediator.
}

sample. Confirmation of the role of weight and shape concerns in mediating the association between obesity and reduced quality of life may have implications for the clinical management of obesity in individuals with BED, in that a shift in focus from the stabilization of eating behavior to the improvement of body acceptance may be indicated $(10,19)$.

The aim of the present study was to investigate weight and shape concerns and binge eating as potential mediators of the association between obesity and impairment in psychosocial functioning in a large community-based sample of women. We hypothesized that one or both of these variables would mediate any observed effect of obesity on levels of impairment. It should be noted that, for convenience, the terms "impairment in psychosocial functioning," "functional impairment," and "quality of life" are used interchangeably in the present study.

\section{Research Methods and Procedures}

\section{Design and Participants}

The research was conducted as part of the Health and Well-Being of Female Australian Capital Territory (ACT) Residents Study, a two-phase epidemiological study of prevalence, disability, health service use, and "mental health literacy" associated with the more commonly occurring (bulimic-type) eating disorders among young adult women in the ACT region. The ACT is a highly urbanized region that includes the city of Canberra (population 323,000 in 2003) (20).

The study design has been described in detail in several previous publications $(18,20-24)$. In brief, self-report questionnaires were posted to a sample of 10,000 female ACT residents, selected at random from the Electoral Roll and stratified by age in 5-year bands as follows: 18 to 22 years, 23 to 27 years, 28 to 32 years, 33 to 37 years, and 38 to 42 years. The questionnaire included measures of eating disorder psychopathology, health-related quality of life, general psychological distress, height and weight, and sociodemographic information. The last included marital status, number of children, main activity, highest level of education completed, country of birth, first language, and private health insurance. BMI $\left(\mathrm{kg} / \mathrm{m}^{2}\right)$ was calculated from selfreported height and weight. Previously, we found a very high correlation $(r=0.97)$ between BMI calculated in this way and BMI calculated according to measured height and weight (25).

Completed questionnaires were received from 5255 individuals, which represented a response rate of $57.1 \%$ after incorrectly listed addresses $(n=684)$ and individuals away from their homes at the time of the survey $(n=112)$ were taken into account. This is a conservative estimate of true response because not all incorrectly listed addresses will have been identified (26). Only information concerning age was available for non-respondents; however, a detailed 
Table 1. Mean (SD) age, BMI, and socio-demographic characteristics of obese $(n=639)$ and non-obese $(n=$ 4253) participants

\begin{tabular}{|c|c|c|c|c|}
\hline & Non-obese $[$ mean $(\mathrm{SD})]$ & Obese $[$ mean (SD)] & $t$ & $p$ \\
\hline Age (yrs) & $29.96(7.25)$ & 32.40 (6.72) & -8.02 & $<0.001$ \\
\hline BMI $\left(\mathrm{kg} / \mathrm{m}^{2}\right)$ & $22.93(3.02)$ & $35.08(4.70)$ & -87.04 & $<0.001$ \\
\hline Marital status & $\%$ & $\%$ & $\chi$ & \\
\hline Married/living as married & 53.8 & 62.8 & & \\
\hline Single/separated or divorced & 46.2 & 37.2 & 18.27 & $<0.01$ \\
\hline \multicolumn{5}{|l|}{ Children } \\
\hline One or more children & 42.2 & 51.4 & & \\
\hline No children & 57.8 & 48.6 & 19.02 & $<0.01$ \\
\hline \multicolumn{5}{|l|}{ Main activity } \\
\hline Employed full-time & 47.4 & 48.7 & & \\
\hline Not employed full-time & 52.6 & 51.3 & 0.36 & $>0.05$ \\
\hline \multicolumn{5}{|l|}{ Level of education } \\
\hline College completed & 46.9 & 36.0 & & \\
\hline College not completed & 53.1 & 64.0 & 25.55 & $<0.01$ \\
\hline \multicolumn{5}{|l|}{ Country of birth } \\
\hline Australia & 84.6 & 88.5 & & \\
\hline Other & 15.4 & 11.5 & 6.91 & $<0.01$ \\
\hline \multicolumn{5}{|l|}{ First language } \\
\hline English & 91.4 & 93.1 & & \\
\hline Not English & 8.6 & 6.9 & 2.14 & $>0.05$ \\
\hline \multicolumn{5}{|l|}{ Health insurance } \\
\hline Private health insurance & 59.6 & 57.6 & & \\
\hline No private health insurance & 40.4 & 42.4 & 0.79 & $>0.05$ \\
\hline
\end{tabular}

analysis of data from a pilot study found no evidence for the existence of non-response bias (27). The sample comprised $\sim 10 \%$ of the total population of females age 18 to 42 years in the region and was representative of this population with respect to socio-demographic characteristics, including BMI (28). Of the 4892 participants who provided details of height and weight, $639(13.1 \%)$ met the accepted criterion for obesity (BMI $\geq 30 \mathrm{~kg} / \mathrm{m}^{2}$ ). The characteristics of obese and non-obese participants are shown in Table 1.

\section{Assessment of Eating Disorder Features}

Weight and shape concerns and binge eating were assessed with the Eating Disorder Examination Questionnaire (EDE-Q) (29), a 36-item self-report measure derived from the Eating Disorder Examination interview (30). The EDE-Q focuses on the past 28 days and is scored using a 7-point, forced-choice, rating scheme (minimum score $=0$; maximum $=6$ ), with higher scores indicating higher levels of eating disorder psychopathology. Scores on each of four subscales, namely, Restraint, Eating Concerns, Weight Con- cerns, and Shape Concerns, and a global score may be derived from the 22 items addressing attitudinal aspects of eating-disorder psychopathology (20). A high level of agreement between self-report (EDE-Q) and interview (EDE) assessment of weight and shape concerns has been demonstrated in both community and clinical samples (25). In the present study population, scores on the Weight Concerns and Shape Concerns subscales were highly correlated $(r=0.91)$. A composite measure of Weight and Shape Concerns was therefore derived as the average of the 12 items comprising these subscales.

In the EDE-Q, eating disorder (i.e., binge eating and compensatory) behaviors are assessed in terms of the number of episodes occurring during the past 4 weeks. These items do not contribute to subscale scores. Agreement between self-report and interview assessment of binge eating has been found to be somewhat lower and more variable than that of subscale scores, and it is generally assumed that this reflects the inferiority of self-report assessment (25). However, research conducted by the authors supports the 
validity of EDE-Q assessment of binge eating in the present study population (25). In particular, we have found that the regular occurrence of binge eating episodes, as assessed by the EDE-Q, is associated with marked impairment in psychosocial functioning on a range of different outcome measures $(23,24)$.

\section{Assessment of Psychosocial Functioning: Medical Outcomes Study Short-Form Disability Scale (SF-12)}

The SF-12 (31) is a 12-item measure of health-related quality of life derived from the 36-item form (32). Items are summarized into two weighted scales (Physical Component Summary Scale, PCS; Mental Component Summary Scale, MCS), designed to assess impairment in everyday functioning associated with physical and mental health problems. Each scale is scored to have a mean of 50 and standard deviation of 10 (in the U.S. population), with lower scores indicating higher levels of impairment. In this study, only the MCS was considered because we were interested in the association between overweight and impairment in psychosocial functioning rather than limitations associated with impairment in physical health. The Rand scoring method (33) was used in preference to the standard method (31) because prior analysis suggested that the former yields more accurate results in community surveys (34). The Rand scoring method employs factor scores derived by means of oblique, as opposed to orthogonal, factor rotation, thereby avoiding complications associated with the application of factor scores based on orthogonal rotation to constructs that are, in fact, correlated, namely, physical and mental health (34).

\section{Days “Out-of-Role"}

An additional measure of functional impairment included in the questionnaire was the number of days in the past four weeks on which participants were unable to complete their work, study, or household responsibilities because of any problem with their (physical or emotional) health. This is a variation of the "days out-of-role" (DOR) questions used in the U.S. National Comorbidity Study (35).

\section{World Health Organization Quality of Life Brief Assessment Scale (WHOQOL-BREF)}

The WHOQOL-BREF (36) is a 26-item short-form of the WHOQOL quality of life assessment scale (37), yielding scores on 4 domains related to the individual's subjective evaluation of quality of life relating to their physical health, environmental health, psychological health, and social relationships. Criterion and content validity, internal consistency, and test-retest reliability have been established (36). Items are scored on a 5-point scale, with a score of 1 indicating extreme dissatisfaction and a score of 5 indicating extreme satisfaction. Hence, lower mean subscale scores indicate poorer perceived quality of life in specific domains. For the present study, only the Psychological Health (QOL-P) and Social Relationships (QOL-S) subscales were considered. Items of the Psychological Health subscale include: "How satisfied are you with yourself?" while items of the Social Relationships subscale include: "How satisfied are you with the support you get from your friends?"

\section{Definition of Obesity}

For this study, a dichotomous variable was used to indicate whether participants met the accepted criterion for obesity, namely, a BMI of $\geq 30 \mathrm{~kg} / \mathrm{m}^{2}$. A dichotomous variable was used in preference to a continuous variable because we were interested specifically in the effects of obesity on functional impairment, as opposed to associations with impairment across the spectrum of body weight. A cut-off of $30 \mathrm{~kg} / \mathrm{m}^{2}$ was used because this criterion is widely accepted (2).

\section{Statistical Analysis}

The characteristics of obese and non-obese individuals were compared by means of $t$ tests (for continuous variables) or $\chi^{2}$ tests (for categorical variables). Correlations between study variables were calculated using the Pearson coefficient or, where appropriate, Spearman's $\rho$. Multiple linear regression analysis was used to test the hypothesis of mediation, following the methods suggested by Baron and Kenny (38). Specifically, mediation is tested by means of three regression equations. First, the dependent variable (DV) is regressed on the independent variable (IV); second, the putative mediator (M) is regressed on IV; third, the DV is regressed on both the IV and M. To establish mediation: 1) IV must affect DV in the first equation; 2) IV must affect $\mathrm{M}$ in the second equation; and 3) $\mathrm{M}$ must affect DV in the third equation. If these conditions all hold in the predicted direction, then the effect of the independent variable on the dependent variable must be less in the third equation than in the second equation (38). Complete or perfect mediation is said to occur if the IV has no effect when M is controlled. Partial mediation occurs if the strength of the relation between IV and DV is reduced when $\mathrm{M}$ is included in the model but is nevertheless greater than zero $(38,39)$. The methods of Baron and Kenny were chosen in preference to those outlined in more recent discussions of mediation effects (e.g., reference 40) because they are widely known and because the putative advantages of the newer methods in terms of statistical power have been found to be negligible when the sample size is large $(39,40)$.

Separate analyses were conducted for each of the four DVs, namely, the SF-12 MCS, the WHOQOL-BREF QOL-P and QOL-S, and DOR, and for each of the two putative mediators, namely, weight and shape concerns and binge-eating frequency (as assessed by the EDE-Q). In each analysis, the IV, obesity, was entered as a dichotomous 
Obesity, Eating Disorder Features, and Quality of Life, Mond et al.

Table 2. Mean (SD) scores on measures of quality of life and eating disorder psychopathology for obese $(n=$ 639) and non-obese $(n=4253)$ participants

\begin{tabular}{lccrr}
\hline & Non-obese [mean (SD)] & Obese [mean (SD)] & $\boldsymbol{t}$ & $\boldsymbol{p}^{*}$ \\
\hline MCS (ref. 31) & $44.62(9.94)$ & $42.67(10.33)$ & 4.57 & $<0.001$ \\
QOL-P (ref. 36) & $3.66(0.61)$ & $3.47(0.69)$ & 6.98 & $<0.001$ \\
QOL-S (ref. 36) & $3.76(0.79)$ & $3.60(0.86)$ & 4.69 & $<0.001$ \\
DOR (ref. 35) & $2.03(4.01)$ & $2.95(5.35)$ & -4.94 & $<0.001$ \\
EDE-Q (ref. 29) & $1.38(1.18)$ & $2.41(1.29)$ & -20.16 & $<0.001$ \\
Weight/shape concerns* & $1.99(1.54)$ & $3.43(1.59)$ & -21.79 & $<0.001$ \\
Binge frequency $\dagger$ & $1.04(3.69)$ & $2.28(5.86)$ & -7.21 & $<0.001$
\end{tabular}

SD, standard deviation; MCS, SF-12 Mental Component Summary Scale; SF-12, Medical Outcomes Study Short-Form Disability Scale; WHOQOL-BREF, World Health Organization Quality of Life Brief Assessment Scale; QOL-P, WHOQOL-BREF Psychological Health subscale; QOL-S, WHOQOL-BREF Social Relationships subscale; DOR, "days out-of-role"; EDE-Q, Eating Disorder Examination Questionnaire. Lower scores on the MCS, QOL-P, and QOL-S indicate higher levels of impairment.

* EDE-Q Weight and Shape Concerns subscale composite measure (30).

$\uparrow$ Number of binge eating (objective bulimic) episodes during the past 28 days, as assessed by the EDE-Q.

variable (non-obese, obese), as outlined above. To test the significance of the mediation effects, that is, the significance of the reduction in the strength of the IV-DV relation, a " $\mathrm{z}$ " score was calculated as:

$$
a b / b^{2} \mathrm{~s}_{\mathrm{a}}{ }^{2}+\mathrm{a}^{2} \mathrm{~s}_{\mathrm{b}}{ }^{2}+\mathrm{s}_{\mathrm{a}}{ }^{2} \mathrm{~s}_{\mathrm{b}}{ }^{2}
$$

where $\mathrm{a}$ and $\mathrm{b}$ are the unstandardized regression coefficients representing the paths between IV and $\mathrm{M}$ and between $\mathrm{M}$ and DV, respectively, and $\mathrm{s}_{\mathrm{a}}$ and $\mathrm{s}_{\mathrm{b}}$ are their standard errors (39). Confidence intervals were calculated as ab $\pm 1.96 \mathrm{~S}_{\mathrm{ab}}$, where $S_{a b}$ is the standard error of the mediated effect (41).

A conservative approach to the selection of variables for the regression analysis was adopted, such that all potential covariates were included in the regression models even if these did not differ significantly between obese and nonobese subgroups in bivariate analysis (42). The following covariates were included in all analyses: age; marital status (married/living as married, not married); children (one or more children, no children); main activity (employed fulltime, other); education level (tertiary studies completed, tertiary studies not completed); country of birth (Australia, other); first language (English, other); and private health insurance (yes, no). All analyses were conducted using SPSS, version 14.0 (SPSS, Inc., Chicago, IL).

\section{Results}

Mean scores for obese and non-obese participants on each of the study variables are given in Table 2 . It can be seen that scores on the MCS, QOL-P, and QOL-S were significantly lower (indicating higher levels of impairment), among obese individuals than non-obese participants, whereas mean DOR, levels of weight and shape concerns, and binge-eating frequency, were significantly higher among obese individuals. The proportion of participants who reported regular (at least weekly) binge eating episodes was also significantly higher among obese participants than non-obese participants $\left(20.3 \%\right.$ vs. $9.0 \%, \chi^{2}=76.54, p<$ $0.01)$.

Correlations between study variables in the total sample are given in Table 3. Among the dependent variables, correlations ranged from -0.21 (QOL-S and DOR) to 0.74 (MCS and QOL-P). Low to moderate positive correlations were observed between Weight and Shape Concerns and both binge-eating frequency (0.36) and obesity (0.28).

Results of the regression analyses are summarized in Table 4, while results of the corresponding tests of significance are summarized in Table 5. For weight and shape concerns, the conditions for complete mediation were satisfied for all 4 dependent variables, since there was no association between obesity and functional impairment when weight and shape concerns were included in the model. Further, after controlling for weight and shape concerns, there was a significant association between obesity and higher scores (indicating lower levels of impairment) on the MCS and a trend toward a similar association between obesity and scores on the QOL-P $(p=0.07)$. For binge frequency, the conditions for partial mediation were satisfied since, for each dependent variable, the strength of the association between obesity and quality of life was significantly reduced, but nevertheless still greater than zero, when binge-eating frequency was included in the regression model. The results were unchanged when the occurrence of regular (at least weekly) binge eating, rather than binge- 
Table 3. Correlations (Pearson's $r$ or Spearman's $\rho$ ) between study variables in the total sample $(n=5255)$

\begin{tabular}{|c|c|c|c|c|c|c|}
\hline & Obesity & MCS & QOL-P & QOL-S & DOR & EDE-Q \\
\hline Obesity & - & & & & & \\
\hline MCS (ref. 31) & -0.06 & - & & & & \\
\hline QOL-P (ref. 36) & -0.09 & 0.74 & - & & & \\
\hline QOL-S (ref. 36) & -0.06 & 0.46 & 0.57 & - & & \\
\hline DOR (ref. 35) & 0.05 & -0.49 & -0.39 & -0.21 & - & \\
\hline Weight/shape concerns & 0.28 & -0.38 & -0.41 & -0.28 & 0.17 & - \\
\hline Binge frequency & 0.12 & -0.20 & -0.21 & -0.13 & 0.14 & 0.36 \\
\hline
\end{tabular}

MCS, SF-12 Mental Component Summary Scale; SF-12, Medical Outcomes Study Short-Form Disability Scale; WHOQOL-BREF, World Health Organization Quality of Life Brief Assessment Scale; QOL-P, WHOQOL-BREF Psychological Health subscale; QOL-S, WHOQOL-BREF Social Relationships subscale; DOR, "days out-of-role"; EDE-Q, Eating Disorder Examination Questionnaire (29). For a sample size of 5255, a correlation of 0.04 is significant at the 0.01 level (two-tailed).

eating frequency, was the mediator. Hence, only results of the original analysis are reported here.

\section{Discussion}

We tested the hypothesis that the association between obesity and impairment in psychosocial functioning is mediated by levels of weight and shape concerns and/or bingeeating frequency. In the case of weight and shape concerns, the conditions for complete mediation were satisfied on each of 4 different measures of impairment. Further, obesity was associated with higher scores (indicating lower levels of impairment) on 2 of the 4 dependent variables, after weight and shape concerns were controlled. In the case of binge-eating frequency, and whereas the conditions for partial mediation were satisfied on each dependent measure, associations between obesity and functional impairment remained highly significant after binge frequency was controlled. Hence, in this study, participants' levels of weight and shape concerns were a more potent mediator of the effect of obesity on psychosocial functioning than binge eating. These findings extend those of earlier studies suggesting that chronic physical ailments and/or pain mediate the association between obesity and impairment in psychosocial functioning $(8,9)$.

The finding that weight and shape concerns were a more potent mediator of the association between obesity and impairment in psychosocial functioning than binge eating is notable, since the significance of binge eating has been emphasized in both the obesity and eating disorders literature $(2,3)$. Recently, however, researchers in eating disorders have begun to focus on the clinical significance of weight and shape concerns among obese binge eaters $(19,43)$. In particular, it has been suggested that a diagnostic criterion reflecting the "undue influence of weight or shape on self-evaluation" may be as relevant for BED as it is for anorexia nervosa and bulimia nervosa $(19,24)$. Inclusion of the "undue influence" criterion for BED in future revisions of the DSM would be consistent with a "trans-diagnostic" view of eating disorders, in that the over-evaluation of weight or shape would be seen as a core diagnostic feature of all eating disorders (44).

If it is accepted that the improvement of quality of life is the ultimate goal of interventions for obesity (8), then identification of the specific variables that mediate the effect of obesity on quality of life has implications for the clinical management of individuals seeking treatment for weight loss. Currently, the focus of eating-disorder-based treatments for BED is on the stabilization of eating behavior, so that the effectiveness of treatment is measured primarily in terms of the reduction or cessation of binge eating (45). If, however, other aspects of eating disorder psychopathology are found to be more central to the obese patient's quality of life, then a focus on binge eating behavior may be counterproductive. With respect to the role of extreme weight or shape concerns in particular, because the presence of these concerns is not included in the criteria for BED suggested in DSM-IV, their significance in the treatment process may be overlooked. Both the stabilization of eating behavior and the improvement of body image are likely to be associated with improved quality of life among obese individuals who binge eat, irrespective of weight loss $(19,45)$. However, communication of the significance of body image dissatisfaction in terms of quality of life may be conducive to a greater focus on self-acceptance as a goal of treatment (46). Further research is needed to elucidate the potential benefits of incorporating a body-image component within obesity treatment programs (10). 


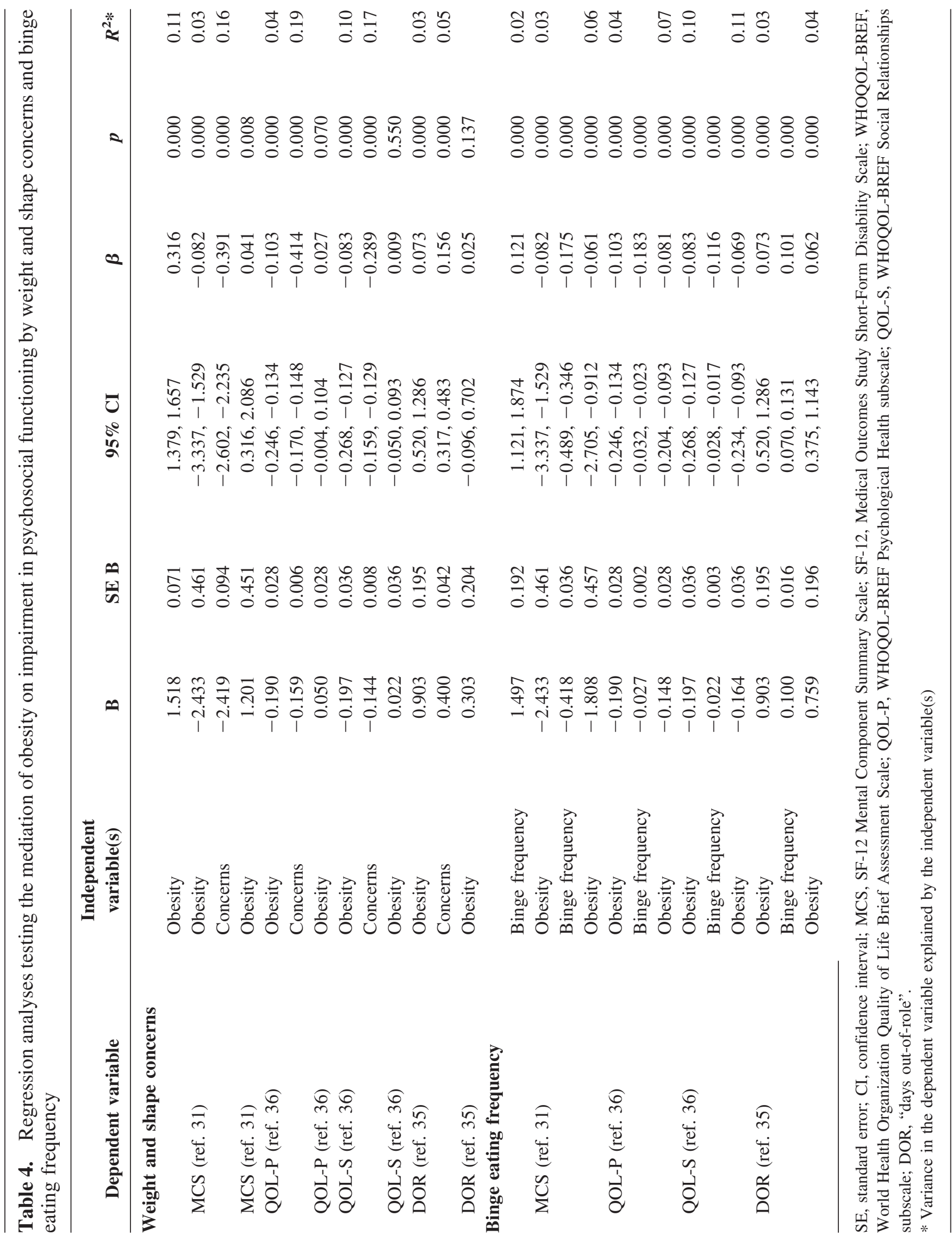


Table 5. Summary of the results of significance tests of the mediation of obesity on impairment in psychosocial functioning by weight and shape concerns and by binge eating frequency

\begin{tabular}{lcccccccccc}
\hline \multicolumn{1}{c}{ Dependent variable } & $\mathbf{a}$ & $\mathbf{s}$ & $\mathbf{b}$ & $\mathbf{s}_{\mathbf{b}}$ & $\mathbf{a}^{\mathbf{2}}$ & $\mathbf{s a}^{\mathbf{2}}$ & $\mathbf{b}^{\mathbf{2}}$ & $\mathbf{s b}^{\mathbf{2}}$ & $\mathbf{z}^{\mathbf{i}}$ & $\mathbf{9 5 \%} \mathbf{C I}$ \\
\hline Weight and shape concerns & & & & & & & & & & \\
$\quad$ MCS (ref. 31) & 1.518 & 0.071 & -2.419 & 0.094 & 2.304 & 0.005 & 5.852 & 0.009 & -16.44 & $-4.11,-3.23$ \\
QOL-P (ref. 36) & 1.518 & 0.071 & -0.159 & 0.006 & 2.304 & 0.005 & 0.025 & 0.000 & -16.63 & $-0.27,-0.21$ \\
QOL-S (ref. 36) & 1.518 & 0.071 & -0.144 & 0.008 & 2.304 & 0.005 & 0.021 & 0.000 & -13.76 & $-0.25,-0.19$ \\
DOR (ref. 35) & 1.518 & 0.071 & 0.400 & 0.042 & 2.304 & 0.005 & 0.160 & 0.002 & 8.69 & $0.47,0.74$ \\
Binge eating frequency & & & & & & & & & & \\
MCS (ref. 31) & 1.497 & 0.192 & -0.418 & 0.036 & 2.241 & 0.037 & 0.175 & 0.001 & -6.46 & $-0.82,-0.44$ \\
QOL-P (ref. 36) & 1.497 & 0.192 & -0.027 & 0.002 & 2.241 & 0.037 & 0.001 & 0.000 & -6.74 & $-0.05,-0.03$ \\
QOL-S (ref. 36) & 1.497 & 0.192 & -0.022 & 0.003 & 2.241 & 0.037 & 0.000 & 0.000 & -5.32 & $-0.05,-0.02$ \\
DOR (ref. 35) & 1.497 & 0.192 & 0.100 & 0.016 & 2.241 & 0.037 & 0.010 & 0.000 & 4.85 & $0.09,0.21$
\end{tabular}

CI, confidence interval; MCS, SF-12 Mental Component Summary Scale; SF-12, Medical Outcomes Study Short-Form Disability Scale; WHOQOL-BREF, World Health Organization Quality of Life Brief Assessment Scale; QOL-P, WHOQOL-BREF Psychological Health subscale; QOL-S, WHOQOL-BREF Social Relationships subscale; DOR, "days out-of-role". Where a and b are the unstandardized regression coefficients representing the paths between the independent variable (IV) and mediator (M), and between $\mathrm{M}$ and the dependent variable (DV), respectively, $\mathrm{s}_{\mathrm{a}}$ and $\mathrm{s}_{\mathrm{b}}$ are their standard errors, and $\mathrm{z}=\mathrm{ab} / \mathrm{b}^{2} \mathrm{~s}_{\mathrm{a}}{ }^{2}+\mathrm{a}^{2} \mathrm{~s}_{\mathrm{b}}{ }^{2}+\mathrm{s}_{\mathrm{a}}{ }^{2} \mathrm{~s}_{\mathrm{b}}{ }^{2}(39)$. A " $\mathrm{z}$ " score of $\geq \pm 2.54$ is significant at the 0.01 level for a two-tailed test.

\section{Strengths, Limitations, and Other Considerations}

There were several notable strengths of the present study. First, we were able to examine associations between obesity, eating-disordered behavior, and quality of life in a large and representative general population sample of women, thereby avoiding biases inherent in the use of treatment-seeking samples $(16,17)$. Second, inclusion of a comprehensive measure of eating disorder psychopathology permitted differentiation of the role of weight and shape concerns from that of binge-eating frequency. Third, several different measures of functional impairment were used. The fact that similarly robust findings were observed on all 4 measures lends credence to the findings. In addition, the fact that the inter-correlations between the different measures of impairment varied considerably suggests that these measures were not simply different measures of the same construct. Finally, we applied established statistical methods to directly test the hypothesis of mediation for each dependent variable.

There were also limitations of the present research. First, because measures of chronic medical illness and pain were not included in the Health and Well-Being Study, it was not possible to consider the relative importance of these and other potential covariates. Given the range of variables potentially contributing to impairment in psychosocial functioning, it is not surprising that the amount of variance explained by obesity and eating disorder features combined did not exceed $20 \%$ for any of the dependent variables. In this regard, it should be noted that aspects of eating disorder psychopathology not considered in the present study, such as levels of dietary restriction and eating concerns, might also be found to mediate the association between obesity and impairment in psychosocial functioning. Obesity is associated with a wide range of eating disorder features, all of which may make independent contributions to levels of general psychological distress (18). We focused on the roles of binge eating and weight and shape concerns because these features have received the most attention in the eating disorders literature and because there is good a priori evidence to support the roles of both (2).

Second, the use of a cross-sectional study design limits any inferences concerning the direction of the observed relationships. Although the findings support a role of eating disorder psychopathology in mediating the association between obesity and quality of life, it is likely that a prospective analysis would reveal reciprocal relationships between obesity, eating-disordered behavior, and quality of life $(47,48)$.

Third, only generic measures of functional impairment were included. The advantage of these measures is that they permit comparison of the effects of different disease states on quality of life, whereas disease-specific measures are likely to be more sensitive to the effects of a given condition on specific aspects of functioning $(15,17)$.

Fourth, we considered only one possible definition of obesity, namely, a BMI of $\geq 30 \mathrm{~kg} / \mathrm{m}^{2}$. We acknowledge 
that different results might have been obtained with a different threshold. It would be of interest to test this hypothesis in future research.

Finally, it should be reiterated that approximately $40 \%$ of individuals selected to participate at the first phase of the study chose not to return a completed questionnaire. Although a detailed analysis of data from a pilot study found no evidence for the existence of response bias on any of the study measures (27), differences between respondents and non-respondents on unmeasured characteristics cannot be excluded.

Interpretation of the present findings is necessarily limited to the associations between obesity, eating-disordered behavior, and quality of life in women. Because eatingdisordered behavior is likely to be experienced differently by men and women (14), associations between obesity, eating-disordered behavior, and quality of life are also likely to differ for men and women. For example, evidence suggests that binge eating is not associated with the same high levels of distress in men as in women (49). This finding likely reflects, at least in part, the fact that the prevalence of extreme weight and shape concerns is lower in men $(3,50)$. Similarly, gender differences in the prevalence of weight and shape concerns and/or the way in which these concerns are experienced, may account for the finding, reported in some community-based studies, that obesity is associated with elevated levels of anxiety and depression in women, but not in men $(51,52)$. Gender-specific associations between overweight and impairment in psychosocial functioning, as well as other adverse outcomes, such as attention and behavior problems, also have been reported in general population samples of children and adolescents $(53,54)$. It has been suggested that these findings may reflect higher levels of body image dissatisfaction and/or a greater susceptibility to weight-related teasing in girls than in boys $(53,54)$.

Interestingly, in the present study, obesity was associated with lower levels of impairment on 2 of the 4 dependent variables, namely, the SF-12 MCS and the Psychological Health subscale of the WHOQOL-BREF, after weight and shape concerns were included in the regression models. Although this finding awaits replication in a different sample, it is possible that young adult women who are overweight but who have low levels of weight and shape concerns constitute a subgroup who function at above-average levels when compared with the population of young adult women as a whole, at least in the specific aspects of functioning assessed by the SF-12 and WHOQOL-BREF. It may be that future research will identify characteristics of obese women that are conducive to better mental health, the effects of which are more apparent among subgroups of individuals with low levels of weight or shape concerns.

Finally, it should be noted that the role of "body image dissatisfaction" or "weight and shape concerns" in mediating the association between obesity and impairment in psychosocial functioning is likely to depend on the way in which these terms are operationalized. In the eating disorder literature, there has been some confusion concerning how best to conceptualize and, in turn, assess the disturbance in body image that is characteristic of eating disorder patients (24). Findings from recent studies suggest that there is a need to distinguish between the over-evaluation of weight or shape and the more general construct of "body image dissatisfaction" $(43,55,56)$. In the present study, weight and shape concerns were assessed using the full subset of items of the EDE-Q Weight Concern and Shape Concern subscales, as opposed to the specific items addressing the over-evaluation of weight or shape (24). In practice, there is no clear separation between "normative" weight or shape concerns and "over-evaluation" of weight or shape, and this boundary may be particularly problematic in obese individuals (46).

In summary, we found, in a community sample of young adult women, that levels of weight and shape concerns were a potent mediator of the association between obesity and impairment in psychosocial functioning, whereas the role of binge-eating frequency was much less pronounced. These findings support a greater focus on body acceptance in obesity treatment programs.

\section{Acknowledgments}

The Health and Well-Being Study was funded by the Canberra Hospital Private Practice Fund, ACT Health and Community Care, and ACT Mental Health. J.M.M. is supported by a National Health and Medical Research Council Sidney Sax Fellowship.

\section{References}

1. Manson JE, Skerrett PJ, Greenland P, VanItallie TB. The escalating pandemics of obesity and sedentary lifestyle: a call to action for clinicians. Arch Intern Med. 2004;164:249-58.

2. Friedman MA, Brownell KD. Psychological consequences of obesity. In: Fairburn CG, Brownell KD, eds. Eating Disorders and Obesity: A Comprehensive Handbook, 2nd ed. New York, NY: Guilford Press; 2002, pp. 393-8.

3. Wardle J, Cooke L. The impact of obesity on psychological well-being. Best Pract Res Clin Endocrinol Metab. 2005;19: 421-40.

4. Myers A, Rosen JC. Obesity Stigmatization and coping: relation to mental health symptoms, body image, and selfesteem. Int J Obes. 1999;23:221-30.

5. Strauss RS, Pollack HA. Social marginalization of overweight children. Arch Pediatr Adolesc Med. 2003;157:74652.

6. Dixon JB, Dixon ME, O'Brien PE. Depression in association with severe obesity. Arch Intern Med. 2003;163:2058-65.

7. Onyike CU, Crum RM, Lee HB, Lyketsos CG, Eaton WW. Is obesity associated with major depression? Results from the Third National Health and Nutrition Examination Survey. Am J Epidemiol. 2003;158:1139-47.

8. Doll HA, Peterson SEK, Stewart-Brown SL. Obesity and physical and emotional well-being: associations between body 
mass index, chronic illness, and the physical and mental components of the SF-36 questionnaire. Obes Res. 2000;8: $160-70$.

9. Heo M, Allison DB, Faith MS, Zhu S, Fontaine KR. Obesity and quality of life: mediating effects of pain and comorbidites. Obes Res. 2003;11:209-16.

10. Friedman KE, Reichmann SK, Costanzo PR, Musante GJ. Body image partially mediates the relationship between obesity and psychological distress. Obes Res. 2002;10:33-41.

11. Wilfley DE, Wilson GT, Agras WS. The clinical significance of binge eating disorder. Int J Eat Disord. 2003;34(suppl):96106.

12. Rieger E, Wilfley DE, Stein RI, Marino V, Crow SJ. A comparison of quality of life in obese individuals with and without binge eating disorder. Int J Eat Disord. 2005;37:23440 .

13. American Psychiatric Association. Diagnostic and Statistical Manual of Mental Disorders, 4th ed. Washington, DC: American Psychiatric Association; 1994.

14. Striegel-Moore RH, Franko DL. Epidemiology of binge eating disorder. Int J Eat Disord. 2003;34(suppl):19-29.

15. Mond JM, Hay PJ, Rodgers B, Owen C, Beumont PJV. Assessing quality of life in eating disorder patients. Qual Life Res. 2005;14:171-8.

16. Fontaine KR, Bartlett SJ, Barofsky I. Health-related quality of life among obese persons seeking and not currently seeking treatment. Int J Eat Disord. 2000;27:101-5.

17. Kolotkin RL, Crosby RD, Williams GR. Health-related quality of life varies among obese subgroups. Obes Res. 2002;10:748-56.

18. Darby A, Hay PJ, Mond JM, Rodgers B, Owen C. Disordered eating behaviours and cognitions in young women with obesity: relationships with psychological status. Int $J$ Obes (Lond). 2007;31:876-82.

19. Wilfley DE, Schwartz MB, Spurrell EB, Fairburn CG. Using the Eating Disorder Examination to identify the specific psychopathology of binge eating disorder. Int $J$ Eat Disord. 2000;27:259-69.

20. Mond JM, Hay PJ, Rodgers B, Owen C. Eating Disorder Examination Questionnaire (EDE-Q): norms for young adult women. Behav Res Ther. 2006;44:53-62.

21. Mond JM, Rodgers B, Hay PJ, Owen C. Self-recognition of disordered eating among women with bulimic-type eating disorders: a community-based study. Int J Eat Disord. 2006; 39:747-53.

22. Mond JM, Hay PJ, Rodgers B, Owen C, Mitchell JE. Correlates of the use of purging and non-purging methods of weight control in a community sample of women. Aust NZ J Psychiatry. 2006;40:136-42.

23. Mond JM, Hay PJ, Rodgers B, Owen C, Crosby R, Mitchell JE. Use of extreme weight control behaviors with and without binge eating in a community sample of women: implications for the classification of bulimic-type eating disorders. Int J Eat Disord. 2006;39:294-302.

24. Mond JM, Hay PJ, Rodgers B, Owen C. Recurrent binge eating with and without the 'undue influence of weight or shape on self-evaluation': implications for the diagnosis of binge eating disorder. Behav Res Ther. 2007;45:929-38.
25. Mond JM, Hay PJ, Rodgers B, Owen C, Beumont PJV. Validity of the Eating Disorder Examination Questionnaire (EDE-Q) in screening for eating disorders in community samples. Behav Res Ther. 2004;42:551-67.

26. Mond JM, Rodgers B, Hay PJ, Owen C, Beumont PJV. Effects of questionnaire length and mode of delivery on response rates in an epidemiological study of eating-disordered behaviour. J Clin Epidemiol. 2004;57:1167-71.

27. Mond JM, Rodgers B, Hay PJ, Owen C, Beumont PJV. Non-response bias in a general population survey of eatingdisordered behaviour. Int J Eat Disord. 2004;36:89-98.

28. Australian Bureau of Statistics. Australian Capital Territory in Focus [Catalogue 1307.8]. Canberra, Australia: Australian Bureau of Statistics; 2003.

29. Fairburn CG, Beglin SJ. Assessment of eating disorders: interview or self-report questionnaire? Int J Eat Disord. 1994; 16:363-70.

30. Fairburn CG, Cooper Z. The Eating Disorders Examination, 12th ed. In: Fairburn CG, Wilson GT, eds. Binge Eating: Nature, Assessment and Treatment. New York, NY: Guilford Press; 1993, pp. 317-60.

31. Ware JE, Kosinski M, Keller SD. A 12-item short-form health survey: construction of scales and preliminary tests of reliability and validity. Med Care. 1996;34:220-33.

32. Ware JE, Kosinski M, Keller SD. SF-36 Physical and Mental Health Summary Scales: A User's Manual. Boston, MA: Health Institute, New England Medical Center; 1994.

33. Hays RD. RAND-36 Health Status Inventory. San Antonio, TX: Psychological Corporation; 1998.

34. Windsor TD, Rodgers B, Butterworth P, Anstey KJ, Jorm AF. Measuring physical and mental health using the SF-12: implications for community surveys of mental health. Aust NZ J Psychiatry. 2006;40:797-803.

35. Kessler RC, Frank RG. The impact of psychiatric disorders on work loss days. Psychol Med. 1997;27:861-73.

36. WHOQOL Group. Development of the World Health Organization WHOQOL-BREF Quality of Life Assessment. Psychol Med. 1998;28:551-8.

37. WHOQOL Group. Development of the WHOQOL: rationale and current status. Int J Ment Health. 1994;23:24-56.

38. Baron RM, Kenny DA. The moderator-mediator variable distinction in social psychological research: conceptual, strategic, and statistical considerations. J Pers Soc Psychol. 1986; 51:1173-82.

39. Frazier PA, Tix AP, Barron KE. Testing moderator and mediator effects in counseling psychology research. J Counseling Psychol. 2004;151:115-34.

40. MacKinnon DP, Lockwood CM, Hoffman JM, West SG, Sheets V. A comparison of methods to test mediation and other intervening variable effects. Psychol Methods. 2002;7: 83-104.

41. Shrout PE, Bolger N. Mediation in experimental and nonexperimental studies: new procedures and recommendations. Psychol Methods. 2002;7:422-45.

42. Katz MH. Multivariable Analysis: A Practical Guide for Clinicians, 2nd ed. Cambridge: Cambridge University Press; 2006. 
43. Masheb RM, Grilo CM. The nature of body image disturbance in patients with binge eating disorder. Int J Eat Disord. 2003;33:333-41.

44. Fairburn CG, Cooper Z, Shafran R. Cognitive behaviour therapy for eating disorders: a 'transdiagnostic' theory and treatment. Behav Res Ther. 2003;41:509-28.

45. Devlin MJ, Fischer SE. Treatment of binge eating disorder. In: Wonderlich S, Mitchell J, de Zwann M, Steiger H, eds. Eating Disorders Review: Part 1. Oxford, UK: Radcliffe; 2005, pp. 27-41.

46. Rosen JC. Obesity and body image. In: Fairburn CG, Brownell KD, eds. Eating Disorders and Obesity: A Comprehensive Handbook, 2nd ed. New York, NY: Guilford Press; 2002, pp. 399-402.

47. Richardson LP, Davis R, Poulton R, et al. A longitudinal evaluation of adolescent depression and adult obesity. Arch Pediatr Adolesc Med. 2003;157:739-45.

48. Neumark-Sztainer D, Wall M, Guo J, Story M, Haines J, Eisenberg M. Obesity, disordered eating, and eating disorders in a longitudinal study of adolescents: how do dieters fare 5 years later? J Am Diet Assoc. 2006;106:559-68.

49. Lewinsohn PM, Seeley JR, Moerk KC, Striegel-Moore RH. Gender differences in eating disorder symptoms in young adults. Int J Eat Disord. 2002;32:426-40.

50. Mond MH, Hay PJ. Functional impairment associated with eating disorder behaviours in a community sample of women and men. Int J Eat Disord. 2007;40:391-8.

51. Palinkas LA, Wingard DL, Barrett-Connor E. Depressive symptoms in overweight and obese older adults: a test of the 'jolly fat' hypothesis. J Psychosom Res. 1996;40: $59-66$.

52. Jorm AF, Korten AE, Christensen H, Jacomb PA, Rodgers B, Parslow RA. Association of obesity with anxiety, depression and emotional well-being: a community survey. Aust NZ J Public Health. 2003;27:434-40.

53. Erickson SJ, Robinson TN, Haydel F, Killen JD. Are overweight children unhappy? Body mass index, depressive symptoms, and overweight concerns in elementary school children. Arch Pediatr Adolesc Med. 2000;154:931-5.

54. Datar A, Sturm R. Childhood overweight and elementary school outcomes. Int J Obes (Lond). 2006;30:1449-60.

55. Goldfein JA, Walsh TB, Midlarsky E. Influence of shape and weight on self-evaluation in bulimia nervosa. Int $J$ Eat Disord. 2000;27:435-45.

56. Masheb RM, Grilo CM, Burke-Martindale CH, Rothschild BS. Evaluating oneself by shape and weight is not the same as being dissatisfied about shape and weight: a longitudinal examination in severely obese gastric bypass patients. Int J Eat Disord. 2006;39:716-20. 